\title{
Inhibitory Effects of Salvianolic Acid B on the High Glucose-Induced Mesangial Proliferation via NF-KB-Dependent Pathway
}

\author{
Pei Luo, ${ }^{a}$ Zhenghuai TAN, ${ }^{b}$ Zhifeng Zhang, ${ }^{a}$ Honghao LI, ${ }^{a}$ and Zhengji Mo ${ }^{*, a}$ \\ ${ }^{a}$ West China School of Pharmacy, Sichuan University; No. 17, Section 3, Ren-Min-Nan-Lu Road, Chengdu, Sichuan \\ 610041, P.R. China: and ${ }^{b}$ Sichuan Institute of Chinese Materia Medica; Chengdu, Sichuan 610041, P.R. China. \\ Received March 1, 2008; accepted April 21, 2008; published online April 22, 2008
}

\begin{abstract}
Salvianolic acid B (Sal B) is one of the major water-soluble compounds isolated from Radix Salviae Miltiorrhizae (Danshen in Chinese) that has been reported to be beneficial to treatment of diabetic complications. However, the mechanisms involved in these effects are not discussed in relation to mesangial proliferation via modulation of NF-KB. To explain this, human mesangial cells were pretreated with or without Sal B $\left(0.1,1,10 \mu_{M}\right)$ for $24 \mathrm{~h}$ and stimulated with high glucose $(30 \mathrm{~mm})$. Then the effects of Sal B on mesangial cells proliferation, extracellular matrix production and the possible mechanisms were evaluated by methylthiazoletetrazolium assay, flow cytometry assay, enzyme-linked immunosorbent assay, gelatin zymography assay and western blot assay. These results indicated that Sal B could inhibit high glucose-induced mesangial cells proliferation and extracellular matrix production in a dose-dependent manner, partially through modulating the cell-cycle progress and MMP2 and MMP-9 activities via suppressing NF- $\kappa$ B activation, suggesting that Sal B may be a promising agent for treating diabetic nephropathy.
\end{abstract}

Key words salvianolic acid B; high glucose; proliferation; NF- $\kappa \mathrm{B}$

Diabetic nephropathy is a common cause of renal disease and accounts to significant morbidity and mortality in patient with diabetes. ${ }^{1,2}$ Recently the underlying mechanism of the evolution of diabetic nephropathy, which encompasses a complex of pathological changes, has been considered as a consequence of the inter-action between metabolic and hemodynamic factors. ${ }^{3,4}$ Increasing evidences showed that renal hypertrophy, partly due to the cell proliferation and mesangial expansion, is one of the early key pathologic features of diabetic nephropathy. ${ }^{5,6)}$ On the basis of reports from several different laboratories, hyperglycaemia plays a crucial role in the development of diabetic complications including nephropathy ${ }^{7}$ and high glucose can promote mesangial cell proliferation, glomerular hypertrophy, and extracellular matrix overproduction. ${ }^{8}$ Moreover, suppression of mesangial cells proliferation and extracellular matrix excessive accumulation may be beneficial to clinical therapy ${ }^{9}{ }^{9}$ Therefore, it is of great clinical importance to search for new agents capable of inhibiting human mesangial cells proliferation and extracellular matrix accumulation for the intervention in diabetic renal disease.

Radix Salviae Miltiorrhizae (Danshen in Chinese) is one of the most popular Chinese herbs used for centuries in the management of heart and brain diseases. ${ }^{10,11)}$ Previous reports demonstrated that $\mathrm{S}$. miltiorrhiza and its preparations prevented diabetic nephropathy through inhibiting renal hypertrophy. ${ }^{12)}$ Studies in vitro have also shown that the extracts of S. miltiorrhiza inhibited proliferation and matrix over synthesis in renal mesangial cells. ${ }^{13)}$ These findings were also consistent with the fact that $\mathrm{S}$. miltiorrhiza has widely been used for the treatment of diabetes mellitus in traditional Chinese medicine. Although the clinical efficacy of S. miltiorrhiza has been established, the active compounds and mechanism of S. miltiorrhiza action against diabetic nephropathy were still unclear. The major bioactive constituents of S. miltiorrhiza can be classified into water-soluble components, e.g. danshensu, protocatechuic acid and salvianolic acids ${ }^{14)}$ and lipid-soluble components including diterpenoids tanshi- nones. Salvianolic acid B (Sal B, Fig. 1) has been well considered to have multiple pharmacological activities such as antioxidative effect, ${ }^{15)}$ antifibrogenic effect, ${ }^{16)}$ myocardial salvage effect ${ }^{17)}$ and neuroprotective effect. ${ }^{18,19)}$ Recently many reports revealed that Sal B had potential protective effects in diabetic nephropathy. ${ }^{20,21)}$ But there is insufficient information on its protective properties in diabetic nephropathy cellular model. Therefore, the aim of this study was to investigate whether Sal B could inhibit high glucose-stimulated mesangial proliferation and underlying mechanisms.

\section{MATERIALS AND METHODS}

Drugs and Reagents Salvianolic acid B (purity $>99 \%$ ) was purchased from the Chinese National Institute for the Control of Pharmaceutical and Biological Products (Beijing, China). Human mesangial cells (HMC) were purchased from Clonetics (San Diego, CA, U.S.A.). Cell culture materials were purchased from Gibco-BRL (MD, U.S.A.). 3-(4,5-dimethylthiazol-2-yl)-2,5-diphenyl tetrazolium bromide (MTT) and dimethylsulfoxide (DMSO) were purchased from Sigma Chemical Co. (St. Louis, MO, U.S.A.). The other chemicals used were of the highest analytical grade commercially available.

Cell Culture and Treatment $\mathrm{HMC}$ were maintained at $37^{\circ} \mathrm{C}$ in a humidified atmosphere of $5 \% \mathrm{CO}_{2}$ on culture plates with $10 \%$ fetal bovine serum-supplemented DMEM

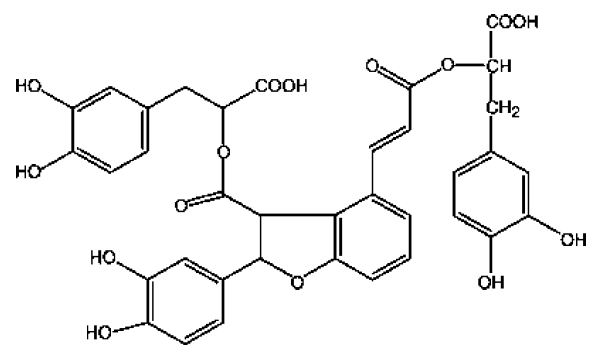

Fig. 1. Chemical Structure of Salvianolic Acid B (Sal B) 
medium. All the subsequent procedures were carried out under these conditions. HMC were pretreated with a series of concentrations of Sal B $(0.1,1,10 \mu \mathrm{M})$ for $24 \mathrm{~h}$ and then stimulated with $30 \mathrm{~mm}$ glucose for $24 \mathrm{~h}$. Cell treatment with Sal B was conducted as follows: control ( $5.5 \mathrm{~mm}$ glucose), High glucose $(30 \mathrm{~mm}$ glucose), low-concentration Sal B (30 mM glucose plus $0.1 \mu \mathrm{M}$ Sal B), medium-concentration Sal B (30 mm glucose plus $1 \mu \mathrm{M}$ Sal B) and high-concentration Sal B (30 mm glucose plus $10 \mu \mathrm{M}$ Sal B). All the glucose used in present study was D-glucose.

MTT Assay Proliferation was examined by MTT assay described by Mosmann ${ }^{22}$ HMC were seeded at $2 \times 10^{4}$ cell/well onto 96 -well plates and preincubated for $24 \mathrm{~h}$. Following incubation with various treatments, a volume of $200 \mu \mathrm{l}$ of $0.5 \mathrm{mg} / \mathrm{ml} \mathrm{MTT} \mathrm{in} \mathrm{DMEM} \mathrm{medium} \mathrm{was} \mathrm{added} \mathrm{to}$ each well. After incubation at $37^{\circ} \mathrm{C}$ for $4 \mathrm{~h}$, the MTT solution was removed from the medium. The resultant formazan crystals were dissolved in $150 \mu \mathrm{l}$ of dimethylulfoxide (DMSO) and the absorbance in each well was then read at $570 \mathrm{~nm}$ using a microplate reader (BioRad 3550, Bio-Rad Laboratories). The arithmetic mean OD of 5 wells for each group was calculated.

Flow Cytometry Assay Changes of cell cycle were analyzed by flow cytometry using PI staining. Briefly, after various treatments, cells were harvested by trypsinization, centrifuged and washed with PBS at room temperature, then fixed in ice-cold $70 \%$ ethanol and stored at $4{ }^{\circ} \mathrm{C}$ for overnight. Then, cells were centrifuged for removal of ethanol at $4{ }^{\circ} \mathrm{C}$ for $10 \mathrm{~min}$ and cellpellets were resuspended in PBS (RNAase $50 \mu \mathrm{g} / \mathrm{ml}$ ) at $37^{\circ} \mathrm{C}$ for $30 \mathrm{~min}$, and stained with propidium iodide in PBS $(40 \mu \mathrm{g} / \mathrm{ml})$ for $30 \mathrm{~min}$ before analysis by flow cytometry (Becton Dickinson, NJ, U.S.A.). Cells were classified as being in G1, S, or G2 depending on the intensity of the fluorescence peaks.

Enzyme-Linked Immunosorbent Assay Cell supernatants were collected for fibronectin using an inhibitory enzyme-linked immunosorbent assay (ELISA) by following the manufacturer's instructions (Shanghai Sun Biotech Co., Ltd.). Briefly, cells were pretreated with Sal B for $24 \mathrm{~h}$ and then stimulate with high glucose for $24 \mathrm{~h}$. After treatments, cells were harvested and the supernatant was collected after being centrifuged for $10 \mathrm{~min}$. Then the samples and fibronectin standard were transferred to 96-well microplates, which has been precoated with specific polyclonal fibronectin antibodies at $4{ }^{\circ} \mathrm{C}$ overnight. The plate was incubated with the reaction mixture at room temperature for $2 \mathrm{~h}$. After washing each well four times, biotinylated rat fibronectin antibodies was added to each well and incubated at room temperature for $1 \mathrm{~h}$. After further four washes, streptavidin-peroxidase conjugate was added and further incubated for $30 \mathrm{~min}$. Then chromogen substrate was added to each well and absorbency at $492 \mathrm{~nm}$ was measured using a microplate reader (BioRad 3550, Bio-Rad Laboratories). Values of each sample were normalized with the protein concentrations measured using Bradford assay.

Gelatin Zymography Assay MMP-2 and MMP-9 activities were determined by gelatin zymography as described previously. ${ }^{23)}$ Briefly, same volume of non-heated cell supernatant were mixed with sample buffer $(2.5 \%$ SDS, $1 \%$ sucrose and $4 \mu \mathrm{g} / \mathrm{ml}$ phenol red), without reducing agent, and applied to $8 \%$ acrylamide gels copolymerized with gelatin at
$1 \mathrm{mg} / \mathrm{ml}$. After electrophoresis, the gels were rinsed twice in $2.5 \%$ Triton X-100 to remove SDS and subsequently incubated in at $37^{\circ} \mathrm{C}$ for $48 \mathrm{~h}$ in a buffer containing $10 \mathrm{mM} \mathrm{CaCl}_{2}$ and $50 \mathrm{~mm}$ Tris- $\mathrm{HCl}(\mathrm{pH} 7.5)$. The gels were then fixed and stained with $0.2 \%$ Coomassie brilliant blue R-250. Proteolytic activity was detected as clear bands in a dark blue field and quantified by densitometry (Kodak Digital Science Image Analysis software).

Preparation of Nuclear Extract and Western Blot Analysis After treatment, cells were harvested and washed twice with ice-cold PBS, and then resuspended in $1 \mathrm{ml}$ of the same buffer. Nuclear extracts were prepared on ice as previously described by the method of Kim et al. ${ }^{24)}$ After centrifugated at $13000 \mathrm{rpm}$, the cell pellet was suspended in ice-cold buffer (10 mм HEPES, $1.5 \mathrm{~mm} \mathrm{MgCl}_{2}, 0.2 \mathrm{~mm} \mathrm{KCl,} 0.2 \mathrm{~mm}$ phenylmethylsulphonylfluoride, $0.5 \mathrm{~mm}$ dithothreitol), vortexed for $10 \mathrm{~s}$ and then centrifuged at $13000 \mathrm{rpm}$ for $5 \mathrm{~min}$. The nuclear pellet was then washed in $1 \mathrm{ml}$ buffer $(20 \mathrm{~mm}$ HEPES, 25\% glycerol, $0.42 \mathrm{M} \mathrm{NaCl}, 1.5 \mathrm{~mm} \mathrm{MgCl}_{2}, 0.2 \mathrm{~mm}$ EDTA), resuspended in $30 \mu \mathrm{l}$ buffer, rotated for $30 \mathrm{~min}$ at $4{ }^{\circ} \mathrm{C}$, then centrifuged for $20 \mathrm{~min}$. The supernatant was used as nucleus extract. The nucleus extracts were then analyzed for protein content using Bradford assay.

Above extract $(70 \mu \mathrm{g})$ was separated on a $12 \%$ sodium dodecyl sulfate (SDS) polyacrylamide gel and transferred to PVDF membrane. Blots were then washed with $\mathrm{H}_{2} \mathrm{O}$, blocked with $5 \%$ skimmed milk powder in TBST $(10 \mathrm{~mm}$ Tris- $\mathrm{HCl}, \mathrm{pH} 7.6,150 \mathrm{~mm} \mathrm{NaCl}, 0.05 \%$ Tween-20) for $1 \mathrm{~h}$ and immunoblotted using against NF- $\kappa \mathrm{B}$ p 65 and $\beta$-actin proteins antibody $(1: 1000)$ for overnight at $4{ }^{\circ} \mathrm{C}$ (Santa Cruz Biotechnology, U.S.A). Then the membrane was washed and primary antibodies were detected with goat anti-rabbit-IgG conjugated to horseradish peroxidase detected by an enhanced chemiluminescence procedure (Amersham, Buckinghamshire, England). Protein expression levels were quantified by densitometry (Kodak Digital Science Image Analysis software).

Statistical Analysis Data were expressed as the mean \pm standard deviation. Statistical analysis of each set of data was carried out using one-way ANOVA and Duncan's multiple range test with SPSS11.5, and $p<0.05$ or $p<0.01$ was considered statistically significant difference among groups.

\section{RESULTS AND DISCCUSION}

Effect of Sal B on High Glucose-Induced HMC Proliferation Human mesangial cells were thought to be involved in the regulation of glomerular microcirculation and the inflammatory response to glomerular injury. ${ }^{25,26)}$ Regardless of different original mechanisms, mesangial cells proliferation might be believed to play predominant roles in the pathogenesis of progressive renal disease. ${ }^{27-29)}$ Hypertrophy of glomerular mesangial cells was associated with the appearance of proteinuria, glomerulosclerosis, and progressive renal failure in many animal models. ${ }^{30)}$ Therefore, the clinical suppression of mesangial overgrowth is critical to prevent renal failure. Additionally, reports have demonstrated that high glucose could promote mesangial cell proliferation. ${ }^{31)}$ In this study, HMC proliferation was evaluated using MTT assay (Fig. 2). Compared with glucose concentration at 


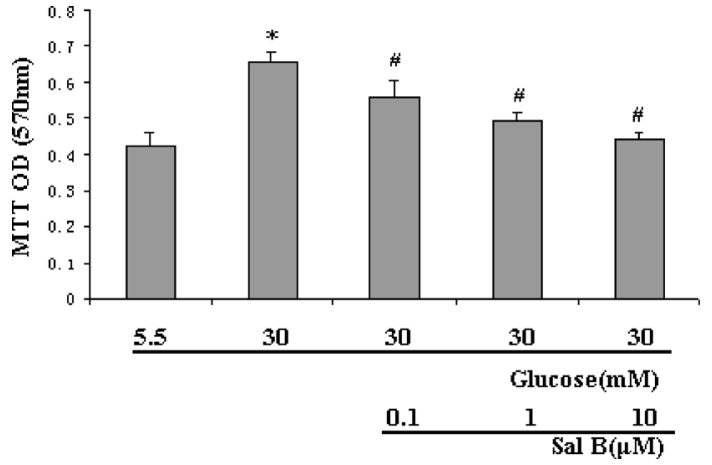

Fig. 2. Effects of Sal B on High Glucose-Induced Proliferation in HMC

HMC were pre-cultured in serum-free medium in the presence or absence of Sal B $(0.1,1,10 \mu \mathrm{M})$ for $24 \mathrm{~h}$, and then stimulated with $30 \mathrm{~mm}$ glucose for $24 \mathrm{~h}$. After differen treatments, cell proliferations were examined by MTT assay. Each bar represented the means \pm S.D. of 5 experiments. $* p<0.05$ compared with control group values $(5.5 \mathrm{~mm}$ glucose-treated); $\# p<0.05$ compared with high glucose group values ( $30 \mathrm{~mm}$ glucosetreated).

$5.5 \mathrm{~mm}$, high glucose $(30 \mathrm{~mm})$ stimulation for $24 \mathrm{~h}$ caused a significant increase in HMC proliferation $(p<0.05)$. Our results showed that pretreatment with Sal B $(0.1,1,10 \mu \mathrm{M})$ significantly suppressed high glucose-induced HMC proliferation in a dose-dependent manner. Moreover, Sal B does not significantly alter viability of HMC until reaching a concentration of $100 \mu \mathrm{M}$ (data not shown). These results strongly suggest that inhibitory effect of Sal B at the concentration used in this study on high glucose-induced HMC proliferation is not mediated by the cytotoxic responses.

Effect of Sal B on High Glucose-Induced Cell Cycle Change in HMC Cell proliferation is considered as a nuclear event and is generally divided into different phases in what is called the cell cycle. ${ }^{32)}$ The available data have demonstrated that proliferation, hypertrophy, and apoptosis of renal injury are linked at the level of the cell cycle. ${ }^{33)}$ Among them, high glucose-induced cell cycle change is intimately associated with diabetic nephropathy and cell cycle regulation may be used for development of future therapeutics. $^{34)}$ To further determine the effects of Sal B on high glucose-induced cell-cycle progression in HMC, we performed flow cytometry analysis (Fig. 3). Compared with control group, incubation with high glucose $(30 \mathrm{~mm})$ resulted in a $44.9 \%$ increase of cells number in G1 phase $(55.8 \pm 4.6 \%$ versus control group 38.5 $44.0 \%, n=3, p<0.05)$ and $19.5 \%$ decrease of cells number in S phase $(16.2 \pm 1.3 \%$ versus control group $20.1 \pm 2.0 \%, n=3, p<0.05)$, indicating that high glucose could effect cell-cycle progression. When HMC were treated with Sal B $(0.1,1,10 \mu \mathrm{M})$ for $24 \mathrm{~h}$ before culture in high glucose medium, G1 phase cells was significantly decreased in a dose-dependent manner compared with single high glucose treatment group $(51.3 \pm 2.0,43.4 \pm 3.8$, $41.3 \pm 5.4 \%$, respectively, $n=3, p<0.05$ versus high glucose group). The pretreatment of Sal B $(1,10 \mu \mathrm{M})$ markedly increased $S$ phase cells $(19.8 \pm 2.7,21.0 \pm 3.5 \%$, respectively, $n=3, p<0.05$ versus high glucose group), while Sal B $(0.1 \mu \mathrm{M})$ slightly increased the percentage of $\mathrm{S}$ phase cells, but the difference was not significant $(p<0.05)$. These results demonstrated that Sal B could block high glucose induced cell-cycle progression via inhibiting the G1-S phase transition and arresting cells at G1 phase.

Effect of Sal B on High Glucose-Induced Fibronectin
Secretion in HMC Fibronectin is one of the major components of the mesangial matrix, and increased synthesis of fibronectin contributes to the mesangial expansion, which is known to play a crucial role in the development of diabetic nephropathy. ${ }^{35)}$ Many previous reports revealed mesangial cells cultured under high glucose exhibited an increase in expression of ECM proteins. ${ }^{36)}$ Early and sequential effects of high glucose on fibronectin mRNA expression and protein synthesis have also been reported. ${ }^{37)}$ In this study, we evaluated whether Sal B could inhibit the secretion of fibronectin induced by high glucose in HMC (Fig. 4). Mesangial cells were seeded in medium containing $30 \mathrm{~mm}$ glucose in the presence or absence of Sal B. Analysis of ELISA of supernatant from mesangial cells was presented in Fig. 4. With the presence of $30 \mathrm{~mm}$ glucose, HMC significantly increased fibronectin secretion $(0.081 \pm 0.023$ versus control group $0.038 \pm 0.011 \mathrm{mg} / \mathrm{mg}, n=6, p<0.05)$. However, pretreatment with Sal B $(0.1,1,10 \mu \mathrm{M})$ significantly attenuated high glucose-induced fibronectin secretion in HMC in a dose-dependent manner $(0.068 \pm 0.009,0.054 \pm 0.013$, $0.048 \pm 0.018 \mathrm{mg} / \mathrm{mg}$, respectively, $n=6, p<0.05$ versus high glucose group).

Effect of Sal B on High Glucose-Induced MMP-2 and of MMP-9 Activity of Zymography Matrix metalloproteinases (MMPs) are zinc-dependent metalloendopeptidases involving in many biological processes. These proteolytic enzymes are believed to play an increasingly recognized role in the regulation of mesangial cell proliferation and extracellular matrix (ECM) accumulation. ${ }^{38)}$ Previous studies showed that expression or activity of MMP increased significantly in case of early diabetic nephropathy. ${ }^{39)}$ And MMP inhibitors can effectively suppress mesangial cell proliferation. ${ }^{40)}$ It has been generally concluded that the basal levels of MMPs in most cell lines are usually low, and that its expression can be induced during hyperglycemia via the activation of transcription factors such as NF- $\kappa \mathrm{B} .{ }^{41)}$ In this study a gelatin zymography assay was used to investigate the inhibition of Sal B on high glucose-induced MMP-2 and MMP-9 secretion. Figure 5 shows a comparative zymogram revealing that the major gelatinolytic activities were observed at molecular masses of 62 and $72 \mathrm{kDa}$, which most likely correspond to the active and latent forms of MMP-2, respectively. A 92-kDa band was also detected in the cell supernatant, which was assigned as MMP-9. HMC grown in Sal B $(10 \mu \mathrm{M})$ without high glucose $(30 \mathrm{~mm})$ for $24 \mathrm{~h}$ do not show virtually any MMP-2 or MMP-9 activity (Data not shown). In comparison to the control group, zymography demonstrated a clear increase of MMP-2 and MMP-9 activities in high glucose induced HMC. However, pretreatment with Sal B $(0.1,1,10 \mu \mathrm{M})$ for $24 \mathrm{~h}$ dramatically decreased their activities.

Effects of Sal B on High Glucose-Induced NF- $\kappa$ B Activation In this study we evaluated the effect of Sal B on the high glucose-induced phosphorylation of p65 subunit in western blotting analysis for NF- $\kappa \mathrm{B}$ activation. NF- $\kappa \mathrm{B}$ exists in the cytoplasm as a latent inactive transcription factor form bound to an inhibitory protein $\mathrm{I}-\kappa \mathrm{B}$ without stimulations and acts as an inducible transcription factor by forming homodimers or heterodimers with proteins of the NF- $\kappa \mathrm{B}$ family, including p65, p50/p105, p52/p100, RelB, and c-Rel. ${ }^{42)}$ Barkett et al. also showed that the increased NF- $\kappa \mathrm{B}$ activation is closely associated with regulation of mesangial cell prolifera- 

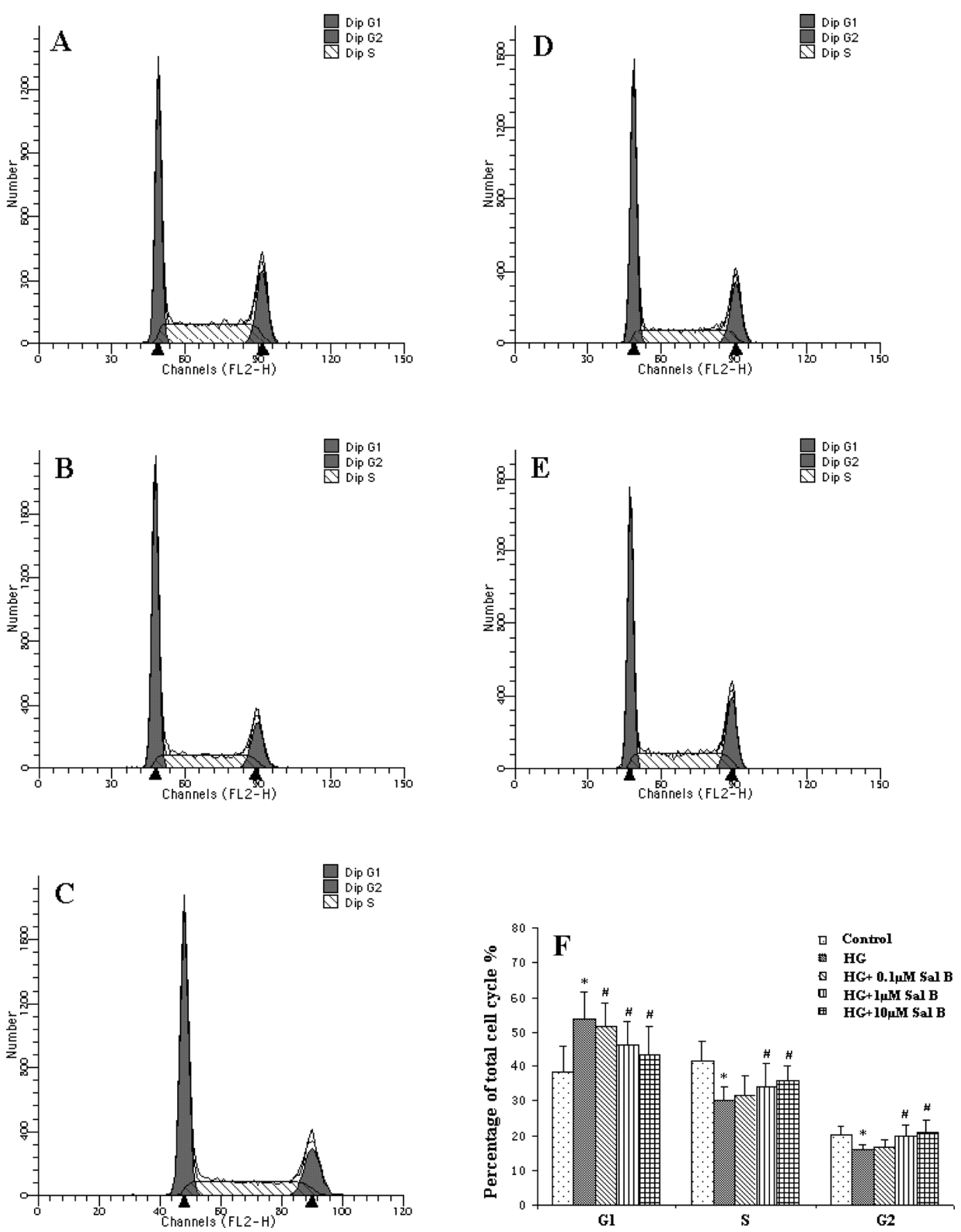

Fig. 3. Effects of Sal B on High Glucose-Induced Cell Cycle Change in HMC

$\mathrm{HMC}$ were pre-cultured in serum-free medium in the presence or absence of Sal B $(0.1,1,10 \mu \mathrm{M})$ for $24 \mathrm{~h}$, and then stimulated with $30 \mathrm{~mm}$ glucose for $24 \mathrm{~h}$. Cellular DNA of these cells was stained with PI and assayed by flow cytometry. (A) Control group (5.5 mm glucose-treated); (B) high glucose group (30 mu glucose-treated); (C) low-concentration Sal B (30 mm glucose plus 0.1 $\mu$ M Sal B-treated); (D) medium-concentration Sal B (30 mm glucose plus $1 \mu \mathrm{m}$ Sal B-treated); (E) high-concentration Sal B (30 mm glucose plus $10 \mu \mathrm{m}$ Sal B-treated); (F) bar graph of the average percentages of G1, S and G2 phase of different treatment. Results are based on cell from 3 experiments. * $p<0.05$ compared with control group values $(5.5 \mathrm{~mm}$ glucose-treated); $\# p<0.05$ compared with high glucose group values ( $30 \mathrm{~mm}$ glucose-treated).

tion. ${ }^{43)}$ When cells are stimulated by inflammatory cytokines, oxidative stress, ultraviolet irradiation, or bacterial endotoxins, NF $-\kappa \mathrm{B}$ is activated by stimulating phosphorylation and degradation of $\left.\mathrm{I}-\kappa \mathrm{B} .{ }^{44,45}\right)$ Then the activated $\mathrm{NF}-\kappa \mathrm{B}$ is translocated into the nucleus, and leads to transcriptional expression of genes associated with cellular growth properties. $^{46)}$ As shown in Fig. 6, high glucose has been shown to induce the phosphorylation of p65, a major subunit of NF$\kappa \mathrm{B}$ leading to their translocations to nucleus, which are required for the transcriptional activities. Thus the transloca- tion of NF- $\kappa \mathrm{B}$ in the nuclear fractions of HMC was significantly increased by treatment with high glucose. However, the concentration over $0.1 \mu \mathrm{M}$ Sal B could inhibit translocation of p65 significantly.

In conclusion, this study showed that Sal B could inhibit high glucose-induced cell proliferation by releasing G1 phase arrest and delaying $\mathrm{S}$ phase progression in human mesangial cells. Additionally, Sal B pretreatment could reduce high glucose-induced fibronectin secretion through modulating MMP-2 and MMP-9, which were closely related 


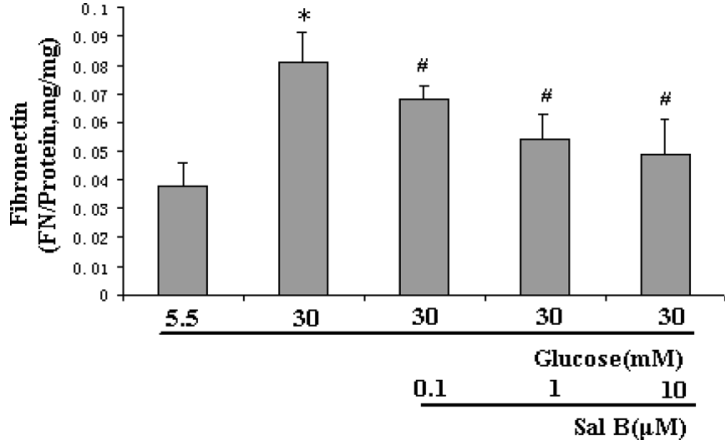

Fig. 4. Effects of Sal B on High Glucose-Induced Fibronectin Secretion in $\mathrm{HMC}$

HMC were pre-cultured in serum-free medium in the presence or absence of Sal B $(0.1,1,10 \mu \mathrm{M})$ for $24 \mathrm{~h}$, and then stimulated with $30 \mathrm{~mm}$ glucose for $24 \mathrm{~h}$. Fibronectin released into the medium were measured with an ELISA kit. Results are expressed as percentages of control. Each bar represents the mean \pm S.D. of 6 experiments. $* p<0.05$ compared with control group values (5.5 mM glucose-treated); \# $p<0.05$ compared with high glucose group values ( $30 \mathrm{~mm}$ glucose-treated).

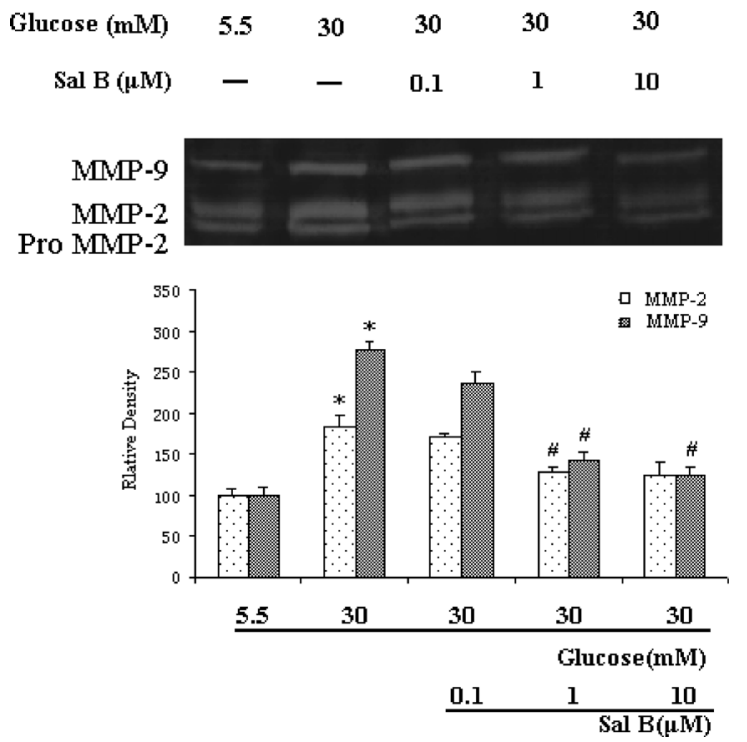

Fig. 5. Effects of Sal B on High Glucose-Induced Enzymatic Activities of MMP-2 and MMP-9 in HMC

HMC were pre-cultured in serum-free medium in the presence or absence of Sal B $(0.1,1,10 \mu \mathrm{M})$ for $24 \mathrm{~h}$, and then stimulated with $30 \mathrm{~mm}$ glucose for $24 \mathrm{~h}$. The activities of MMP-2, active MMP-2, and MMP-9 were determined by gelatinase zymography with cell supernatant. Each bar represents the mean \pm S.D. of 3 experiments. $* p<0.05$ compared with control group values $(5.5 \mathrm{~mm}$ glucose-treated); \# $p<0.05$ compared with high glucose group values ( $30 \mathrm{~mm}$ glucose-treated).

to degradation and accumulation of extracellular matrix. These activities may be partly mediated by blocking the NF$\kappa \mathrm{B}$ activation. The present results were compatible with the renoprotective effect of $\mathrm{S}$. miltiorrhiza extract reported previously and might provided some evidences to explain the mechanism of Sal B action against diabetic nephropathy.

Acknowledgments This work was financed by the Sichuan Youth Science \& Technology Foundation (05ZQ026034).

\section{REFERENCES}

1) King H., Aubert R. E., Herman W. H., Diabetes Care, 21, 1414-1431 (1998).
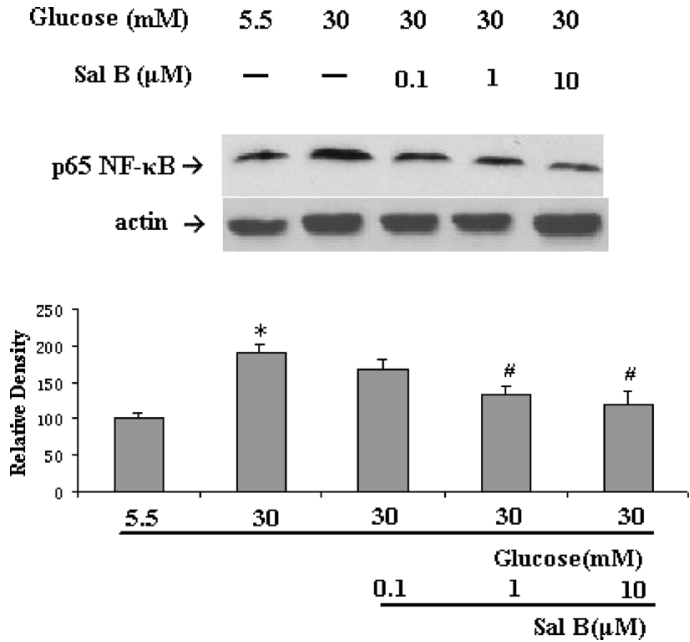

Fig. 6. Effects of Sal B on High Glucose-Induced NF- $\kappa$ B Activation in $\mathrm{HMC}$

HMC were pre-cultured in serum-free medium in the presence or absence of Sal B $(0.1,1,10 \mu \mathrm{M})$ for $24 \mathrm{~h}$, and then stimulated with $30 \mathrm{~mm}$ glucose for $24 \mathrm{~h}$. Each bar represents the mean \pm S.D. of 3 experiments and is expressed relative to a control. $* p<0.05$ compared with control group values ( $5.5 \mathrm{~mm}$ glucose-treated); ${ }^{*} p<0.05 \mathrm{com}$ pared with high glucose group values ( $30 \mathrm{~mm}$ glucose-treated).

2) Mogensen C. E., Diabetes Care, 26, 1631-1632 (2003).

3) Auwardt R., Savige J., Wilson D., Clin. Nephrol., 52, $1-4$ (1999).

4) Cooper M. E., Gilbert R. E., Epstein M., Metabolism, 47, 3-6 (1998).

5) Rabkin R., Fervenza F. C., Diabetes Metab., 12, 217-241 (1996).

6) Kennefick T. M., Anderson S., Semin. Nephrol., 17, 441-447 (1997).

7) Brownlee M., Nature (London), 414, 813-820 (2001).

8) Ha H., Cha M. K., Choi H. N., Lee H. B., Perit. Dial. Int., 22, 171177 (2002).

9) Sharma K., Ziyadeh F. N., Am. J. Physiol., 267, 1094-1101 (1994).

10) Chen W. Z., Wang Z. M., Dong Y. L., Chen L. X., Yao Xue Xue Bao, 14, 326-332 (1979).

11) Tang M. K., Ren D. C., Zhang J. T., Du G. H., Phytomedicine, 9, $405-409$ (2002)

12) Liu G., Guan G. J., Qi T. G., Fu Y. Q., Li X. G., Sun Y., Wu T., Wen R. Z., Zhong Xi Yi Jie He Xue Bao, 3, 459-462 (2005).

13) Xu M., Wang Y. P., Luo W. B., Xuan L. J., Acta Pharmacol. Sin., 22, 629-633 (2001).

14) Chan J., Wang F., Lee F., Wang X., Talant, 69, 172-179 (2006).

15) Soung D. Y., Rhee S. H., Kim J. S., Lee J. Y., Yang H. S., Choi J. S., Yokozawa T., Han Y. N., Chung H. Y., J. Pharm. Pharmacol., 55, $1427-1432$ (2003).

16) Lin Y. L., Wu C. H., Luo M. H., Huang Y. J., Wang C. N., Shiao M. S., Huang Y. T., J. Ethnopharmacol., 105, 215-222 (2006).

17) Cao C. M., Xia Q., Zhang X., Xu W. H., Jiang H. D., Chen J. Z., Life Sci., 72, 2451-2463 (2003).

18) Chen Y. H., Du G. H., Zhang J. T., Acta Pharmacol. Sin., 21, 463466 (2000).

19) Yokozawa T., Dong E., Oura H., Kashiwagi H., Nonaka G., Nishioka I., Nephron., 75 (1), 88-93 (1997).

20) Jung M., Lee H. C., Ahn C. W., Park W., Choi S., Kim H., Cho D., Lee G. T., Li H. R., Chem. Pharm. Bull., 50, 1135-1136 (2002).

21) Lee G. T., Ha H., Jung M., Li H., Hong S. W., Cha B. S., Lee H. C., Cho Y. D., J. Am. Soc. Nephrol., 14, $709-720$ (2003).

22) Mosmann T., J. Immunol. Methods, 65, 55-63 (1983).

23) Kondo S., Kubota S., Shimo T., Nishida T., Yosimichi G., Eguchi T., Sugahara T., Takigawa M., Carcinogenesis, 23, 769-776 (2002).

24) Kim S. O., Kundu J. K., Shin Y. K., Park J. H., Cho M. H., Kim T. Y. Surh Y. J., Oncogene, 24, 2558-2567 (2005).

25) Kashgarian M., Lab. Invest., 52, 569-571 (1985).

26) Lovett D. H., Ryan J. L., Sterzel R. B., J. Immunol., 131, 2830-2836 (1983).

27) Becker G. J., Hewitson T. D., Kidney Int., 59, 1184-1185 (2001).

28) Liu N., Shimizu S., Ito-Ihara T., Takagi K., Kita T., Ono T., Nephron. Exp. Nephrol., 105 (3), 65-74 (2007).

29) Haas C. S., Schöcklmann H. O., Lang S., Kralewski M., Sterzel R. B., 
J. Nephrol., 12, 405-415 (1999).

30) Striker L. J., Doi T., Elliot S., Striker G. E., Semin. Nephrol., 9, $318-$ 328 (1989).

31) Zhang X., Chen X., Wu D., Liu W., Wang J., Feng Z., Cai G., Fu B., Hong Q., Du J., J. Am. Soc. Nephrol., 17, 1532-1542 (2006).

32) Norbury C., Nurse P., Аnпи. Rev. Biochem., 61, 441- 471 (1992).

33) Shankland S. J., Kidney Int., 52, 294-308 (1997).

34) Yin D. K., Yao W. B., Gao X. D., Biol. Pharm. Bull., 30, 2274-2278 (2007).

35) Chen H. C., Guh J. Y., Shin S. J., Lai Y. H., Atherosclerosis, 160, $141-146(2002)$

36) Oh J. H., Ha H., Yu M. R., Lee H. B., Kidney Int., 54, 1872-1878 (1998).

37) Ayo S. H., Radnik R. A., Gloss W. F., Garoni J. A., Rampt E. R., Appling D. R., Kreisberg J. I., Am. J. Physiol., 260, 185-191 (1991).
38) Marti H. P., Transpl. Immunol., 9, 97-100 (2002).

39) Ebihara I., Nakamura T., Noriaki S., Koide H., Am. J. Kidney Dis., 32, $544-550$ (1998)

40) Kuroqi Y., Med. Res. Rev., 23, 15-31 (2003).

41) Auwardt R. B., Mudge S. J., Chen C., Power D. A., Exp. Nephrol., 8, $144-151(2000)$

42) Baldwin A. S., Jr., Annu. Rev. Immunol., 14, 649-683 (1996).

43) Barkett M., Gilmore T. D., Oncogene, 18, 6910—6924 (1999).

44) Bours V., Bonizzi G., Bentires-Alj M., Bureau F., Piette J., Lekeux P., Merville M., Toxicology, 153, 27-38 (2000).

45) Henkel T., Machleidt T., Alkalay I., Kronke M., Ben-Neriah Y., Baeuerle P. A., Nature (London), 365, 182-185 (1993).

46) Sheu J. N., Lin T. H., Lii C. K., Chen C. C., Chen H. W., Liu K. L., Food Chem. Toxicol., 44, 409-416 (2006). 